\title{
Comparison of laboratory- and field-based exercise tests for COPD: a systematic review
}

This article was published in the following Dove Press journal:

International Journal of COPD

19 March 2015

Number of times this article has been viewed

\author{
lain Fotheringham' \\ Georgina Meakin' \\ Yogesh Suresh Punekar ${ }^{2}$ \\ John H Riley ${ }^{2}$ \\ Sarah M Cockle ${ }^{2}$ \\ Sally J Singh ${ }^{3}$ \\ 'Value Demonstration Practice, \\ Oxford PharmaGenesis, Oxford, \\ ${ }^{2}$ GlaxoSmithKline, Uxbridge, \\ ${ }^{3}$ Department of Respiratory Medicine, \\ University Hospitals of Leicester NHS \\ Trust, Leicester, UK
}

\begin{abstract}
Exercise tests are often used to evaluate the functional status of patients with COPD. However, to the best of our knowledge, a comprehensive systematic comparison of these tests has not been performed. We systematically reviewed studies reporting the repeatability and/or reproducibility of these tests, and studies comparing their sensitivity to therapeutic intervention. A systematic review identified primary manuscripts in English reporting relevant data on the following exercise tests: 6-minute walk test (6MWT) and 12-minute walk test, incremental and endurance shuttle walk tests (ISWT and ESWT, respectively), incremental and endurance cycle ergometer tests, and incremental and endurance treadmill tests. We identified 71 relevant studies. Good repeatability (for the 6MWT and ESWT) and reproducibility (for the 6MWT, 12-minute walk test, ISWT, ESWT, and incremental cycle ergometer test) were reported by most studies assessing these tests, providing patients were familiarized with them beforehand. The 6MWT, ISWT, and particularly the ESWT were reported to be sensitive to therapeutic intervention. Protocol variations (eg, track layout or supplemental oxygen use) affected performance significantly in several studies. This review shows that while the validity of several tests has been established, for others further study is required. Future work will assess the link between these tests, physiological mechanisms, and patient-reported measures.
\end{abstract}

Keywords: 6MWT, 12MWT, COPD, walk test, repeatability, reproducibility, shuttle walk test, cycle ergometer test

\section{Introduction}

COPD is a leading cause of death worldwide, and the prevalence of the disease is projected to increase as the population ages and as exposure to risk factors, such as smoking, continues. ${ }^{1-3}$ COPD is characterized by symptoms of breathlessness and reduced exercise capacity. ${ }^{4,5}$ Decrements in exercise capacity can result in reduced ability to perform activities of daily living, and the resultant inactivity and sedentary lifestyle can further exacerbate exercise impairment (the COPD "vicious circle"). ${ }^{6}$

In clinical practice, spirometry is recommended by the Global Initiative for Chronic Obstructive Lung Disease (GOLD) for the diagnosis of COPD. ${ }^{5}$ However, the results of spirometry alone poorly predict disability and quality of life in patients with $\mathrm{COPD}^{7}$ and correlate only weakly with dyspnea, exercise capacity, and health status. ${ }^{8-10}$ Recent guidelines on the diagnosis and treatment of COPD indicate that assessment of disease severity is improved by using additional functional criteria such as exercise capacity. ${ }^{4,5,11}$ Quantification of the degree of functional impairment is therefore important for the assessment of response to treatment and as an outcome for clinical trials.

There are a number of laboratory- and field-based tests currently used for the assessment of exercise capacity, including the 6- and 12-minute walk tests (6MWT

\footnotetext{
Correspondence: lain Fotheringham

Oxford PharmaGenesis,

Tubney Warren Barn, Tubney,

Oxford, OXI3 5QJ, UK

Tel +44 I865 390। 44

Fax +44 I865 390I45

Email iain.fotheringham@pharmagenesis. com
} 
and 12MWT, respectively), the incremental and endurance shuttle walk tests (ISWT and ESWT, respectively), the incremental and endurance cycle ergometer tests (ICET and ECET, respectively), and the incremental and endurance treadmill tests (ITT and ETT, respectively). However, there is no consensus about which test is the most appropriate for use in patients with COPD. These tests have different primary outcomes (eg, endurance time, distance, oxygen consumption) that may reflect different physiological parameters. It is therefore difficult to compare results across studies, limiting interpretation of the published literature in this field. Furthermore, the relative merits of different tests have not been established.

The systematic review presented here therefore evaluated evidence of the "repeatability" (defined as consistency of results when multiple tests are conducted on the same day) and the "reproducibility" (consistency of results when tests are conducted on different days) of the tests. The review also assessed the relative properties of the eight commonly used exercise tests and their sensitivity to therapeutic intervention (such as rehabilitative, pharmacological, or surgical procedures). In addition, the effect of protocol variations within each test was assessed across studies. When possible, results were placed in the context of available minimal clinically important difference (MCID) values, which have thus far been ascertained for the 6MWT, ${ }^{12}$ ISWT, ${ }^{13}$ ESWT, ${ }^{14}$ and ICET. ${ }^{12}$ Investigation of these factors will be useful in guiding test selection in clinical practice and for outcome measures in clinical trials. As these tests are often also used as interventions, evaluation of exercise testing modalities in patients with COPD will also inform the clinical development of optimal exercise rehabilitation strategies.

\section{Methods}

\section{Search strategy}

Literature searches were conducted using Ovid ${ }^{\circledR}$ (Ovid Technologies Inc., New York, NY, USA), incorporating Ovid Med$\operatorname{line}^{\circledR}$ (US National Library of Medicine, Bethesda, MD, USA), for the period from 1948 to January 22, 2013, Ovid Embase ${ }^{\text {TM }}$ (Elsevier Inc., Philadelphia, PA, USA) for 1974 to January 22, 2013, and The Cochrane Library (John Wiley and Sons Ltd, Hoboken, NJ, USA) for 1962 to January 22, 2013 (see Tables S1-S3). Search strings were constructed to identify studies reporting primary data on the outcomes of the following exercise tests in patients with COPD: the 6MWT, 12MWT, ISWT, ESWT, ICET, ECET, ITT, and ETT. The full search strings are presented in the "Supplementary materials" section.

\section{Study selection}

Study selection followed the Preferred Reporting Items for Systematic Reviews and Meta-Analyses (PRISMA) guidelines for performing a systematic literature review. ${ }^{15}$ Review articles and studies not published in English were excluded using search-engine filters. Studies confounded by comorbidities (such as cancers, diabetes, and non-COPD respiratory-tract diseases) were excluded on review of title/ abstract. The remaining studies were screened based on titles and abstracts, and full articles were reviewed when their relevance was unclear from the abstract. Screening was performed by a single author (GM) and records were initially reviewed by title/abstract; a full paper review was subsequently undertaken for publications that could not be excluded by title/abstract. Included records were verified by a second author (IF). A 30\% random sample of excluded records was also reviewed by the second author (IF). Disagreements were settled by consultation with the remaining authors.

When reviewing abstracts or full papers, records were excluded if they were reviews, were not in the English language, studied patients with confounding comorbidities (eg, cancers or diabetes), did not use an exercise test as an outcome measure, or examined an intervention other than our interventions of interest (pulmonary rehabilitation, bronchodilator therapy, and lung-volume reduction surgery). Specific inclusion criteria included any definition of COPD (including emphysema- and bronchitis-specific studies); interventions were included only in our comparison of sensitivity and limited to pulmonary rehabilitation, bronchodilation, and lung-volume reduction surgery. Included test outcomes are outlined in the "Data abstraction" section. Following screening, studies were subsequently included for assessment if they reported data on:

- repeatability (studies reporting data from two or more performances of the same test[s] on the same day under the same conditions)

- reproducibility (studies reporting data from two or more performances of the same test[s] on different days under the same conditions)

- comparisons of sensitivity (studies reporting responses of two or more tests to the following therapeutic interventions: pulmonary rehabilitation, bronchodilator therapy, or lung-volume reduction surgery)

- protocol variations (studies reporting two or more performances of a test when protocol parameters have been modified). 


\section{Data abstraction}

Data were primarily abstracted by a single author (GM) and reviewed by all co-authors. A randomly generated selection of $30 \%$ of all articles was reviewed by a second author (IF) for quality-control purposes.

The following outcomes of exercise tests were recorded: distance or stages achieved for the 6MWT, 12MWT, and ISWT; duration of exercise for the ESWT, ECET, and ETT; and the highest recorded volume of oxygen consumption (peak $\mathrm{VO}_{2}$ ) and/or maximum workload $\left(\mathrm{W}_{\text {max }}\right.$ ) for the ICET and ITT. Articles merited inclusion in this review if they reported: outcomes of the specified tests when performed repeatedly under the same conditions, either on the same day (repeatability) or on different days (reproducibility); changes in response before and after therapeutic intervention (comparison of sensitivity); or effects of within-test variations in protocol (protocol variation).

Studies comparing the sensitivity of tests were also assessed for expression by the authors of preference for any specific test. When distances were reported in feet, values were converted to meters using standard conversion criteria stated by the International Bureau of Weights and Measures ( 0.3048 meters per foot). Within each publication, tests for which results are available are referred to as "test 1 ", "test 2", etc; occasions on which a test has been described by the authors, but results are not reported (such as for practice tests), are referred to as "familiarizations".

\section{Results}

\section{Overview of identified studies}

The search methodology used to identify relevant articles is summarized in Figure 1. Of 1,781 unique articles screened, 71 were ultimately deemed eligible for inclusion in this review.

\section{Studies assessing the repeatability and reproducibility of tests}

Clinical practice is influenced by factors such as the repeatability and reproducibility of exercise tests in patients with COPD. These factors have been extensively assessed for the 6MWT and 12MWT; data are more limited for the ISWT, ESWT, ITT, and ETT (23 references for the 6/12MWT; 12 for the IWST, ESWT, ITT, and ETT; seven for the ICET and ECET; this made 37 references in total owing to overlap of these categories). Table 1 summarizes the results of studies assessing the repeatability and reproducibility of the 6MWT and 12MWT; Table 2 focuses on the ISWT, ESWT, ETT, and ITT; and Table 3 presents data on the ICET and ECET.

Six studies presented repeatability data for the 6MWT (Table 1) ${ }^{16-21}$ Of these, five reported a significant increase in 6MWT distance from the first to the second test; ${ }^{16-20}$ the remaining study found no differences between results, though patients had been previously familiarized with the tests. ${ }^{21}$ The three studies clearly reporting the results of three $6 \mathrm{MWTs}$ performed on the same day found that there

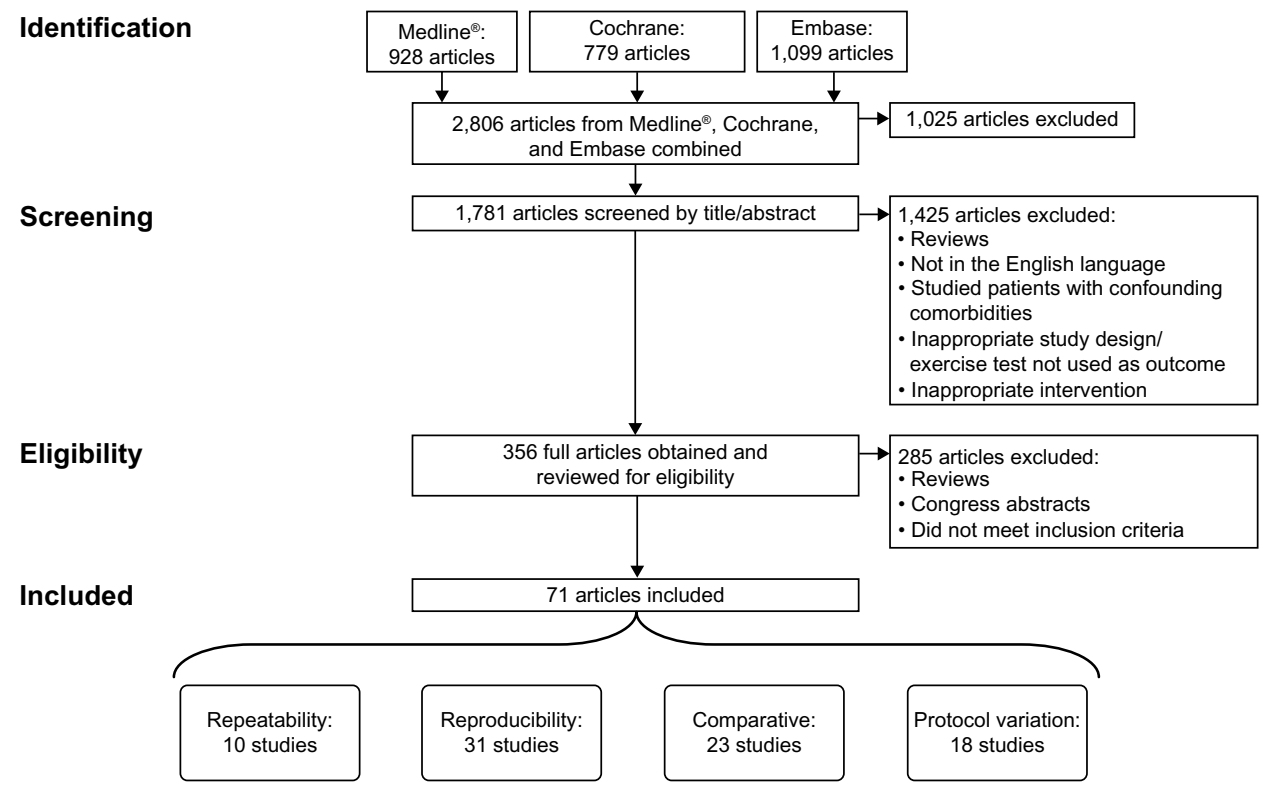

Figure I Preferred Reporting Items for Systematic Reviews and Meta-Analyses (PRISMA) diagram detailing the identification and inclusion process of the articles. Some studies are included in more than one analysis category; consequently, the aggregate number of studies in the repeatability, reproducibility, comparative, and protocol variation groups adds up to more than $7 \mathrm{I}$. 


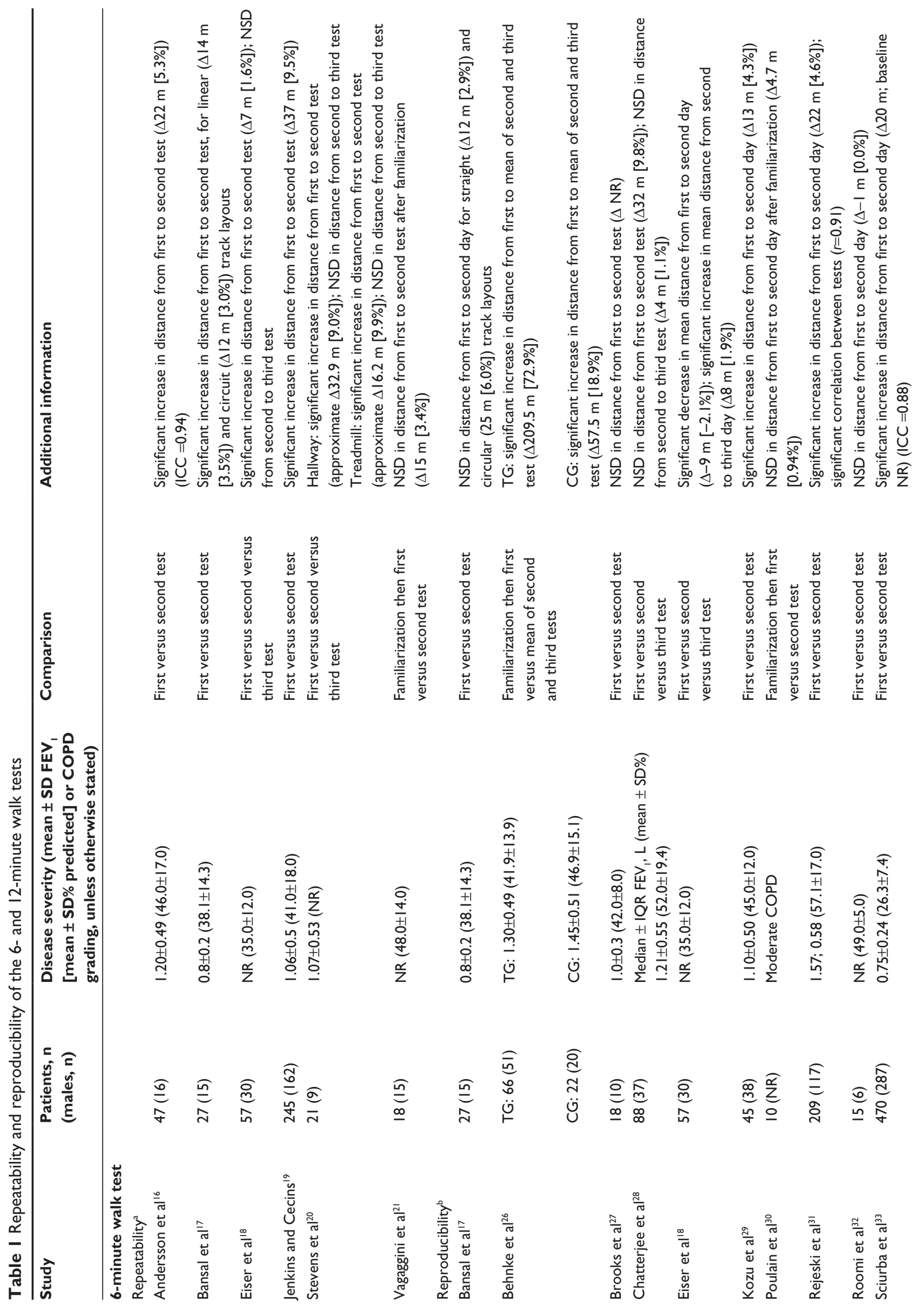




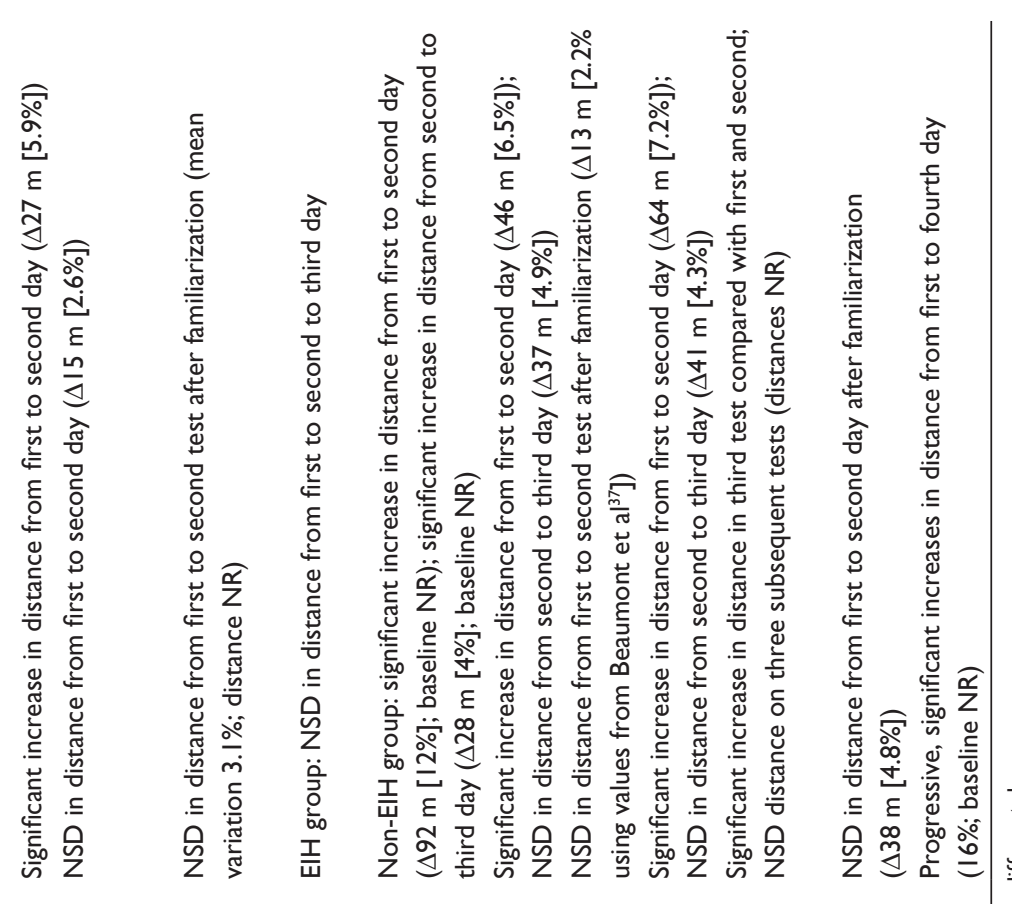

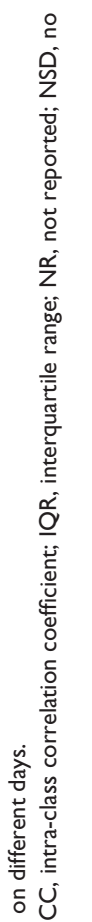

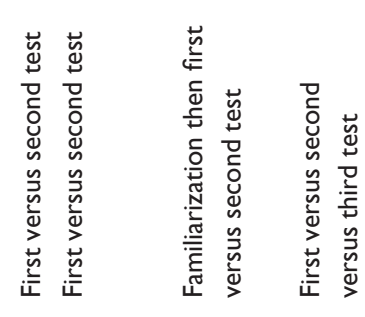

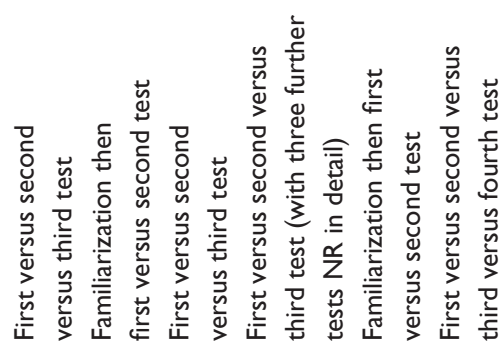

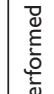

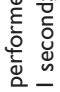

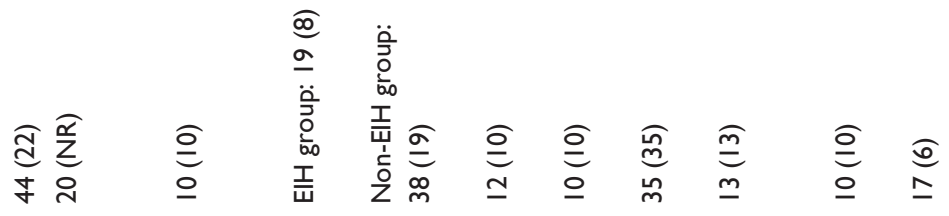
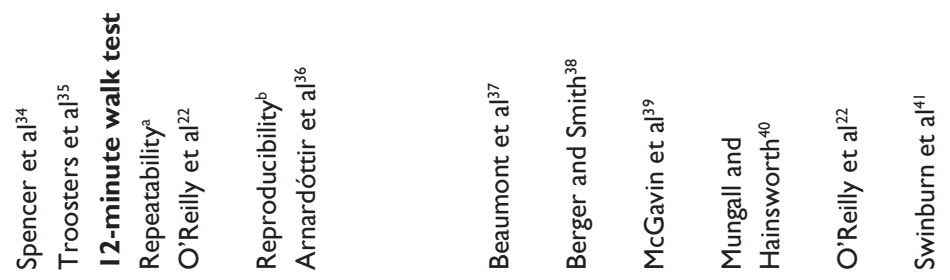


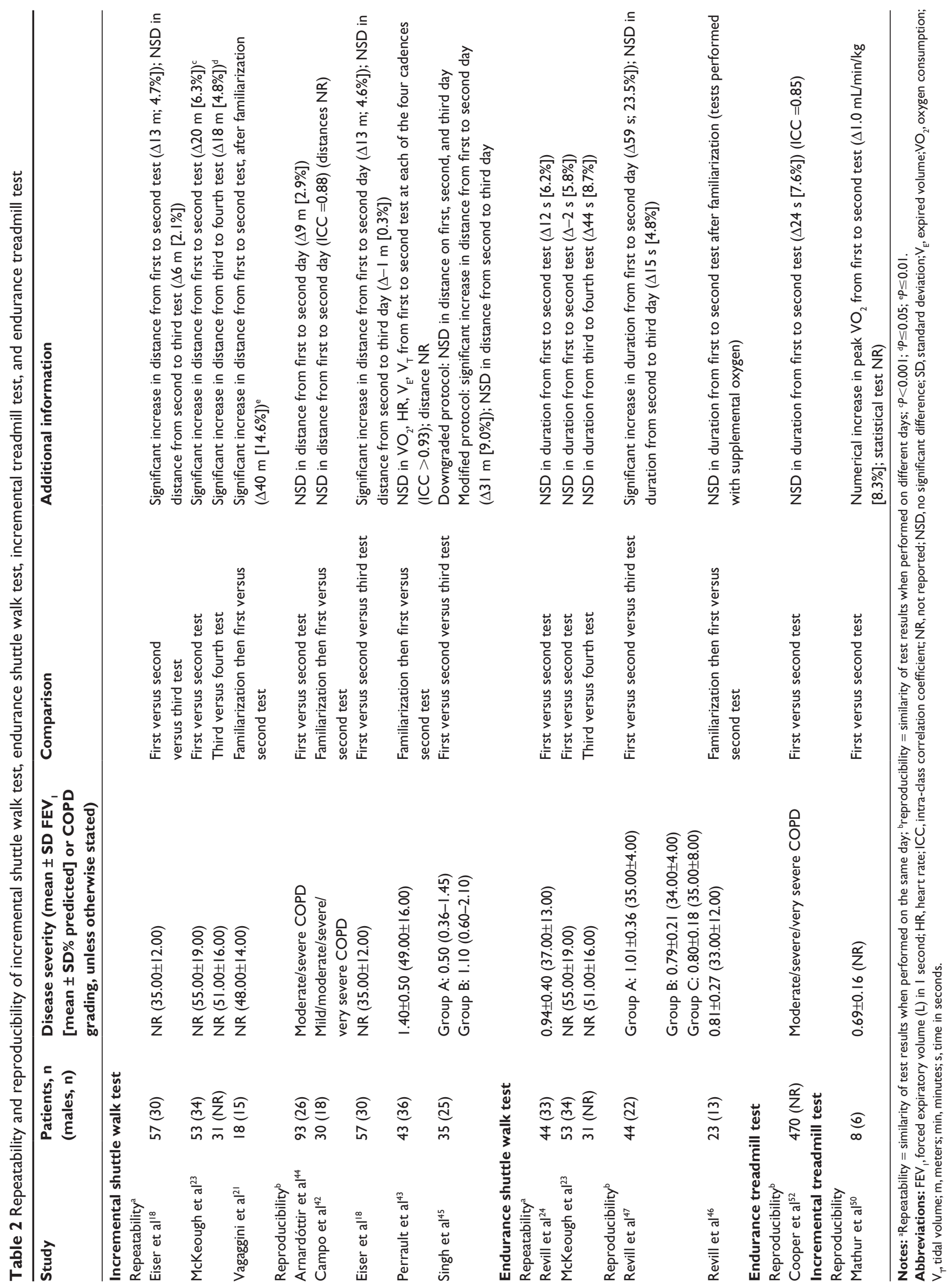


Table 3 Repeatability and reproducibility of cycling tests

\begin{tabular}{|c|c|c|c|c|}
\hline Study & $\begin{array}{l}\text { Patients, } \mathrm{n} \\
\text { (males, n) }\end{array}$ & $\begin{array}{l}\text { Disease severity (mean } \pm \text { SD FEV } \\
\text { [mean } \pm \text { SD } \% \text { predicted] or COPD } \\
\text { grading, unless otherwise stated) }\end{array}$ & Comparison & Additional information \\
\hline \multicolumn{5}{|c|}{ Incremental cycle ergometer test } \\
\hline \multicolumn{5}{|c|}{ Repeatability } \\
\hline Brown et $\mathrm{al}^{25}$ & II (NR) & $1.5 \mathrm{I} \pm 0.59(\mathrm{NR})$ & First versus second test & $\begin{array}{l}\text { NSD in peak } \mathrm{VO}_{2} \text { from first to second test } \\
(\Delta 53 \mathrm{~mL} / \mathrm{min}[4.0 \%]) ; \mathrm{NSD} \text { in } \mathrm{W}_{\text {max }} \text { from } \\
\text { first to second test ( } \triangle 0 \mathrm{~W}[0 \%])\end{array}$ \\
\hline \multicolumn{5}{|l|}{ Reproducibility ${ }^{b}$} \\
\hline Brown et a $\left.\right|^{25}$ & II (NR) & $\mathrm{I} .5 \mathrm{I} \pm 0.59(\mathrm{NR})$ & First versus third test & $\begin{array}{l}\text { NSD in peak } \mathrm{VO}_{2} \text { from first to third test } \\
(\Delta 93 \mathrm{~mL} / \mathrm{min}[7.1 \%]) ; \mathrm{NSD} \text { in } \mathrm{W}_{\max } \text { from } \\
\text { first to third test }(\Delta 0 \mathrm{~W}[0 \%])\end{array}$ \\
\hline Covey et a ${ }^{48}$ & $56(40)$ & NR $(49.00 \pm 16.00)$ & First versus second test & $\begin{array}{l}\text { NSD in peak } \mathrm{VO}_{2} \text { from first to second day } \\
(\Delta 0.0 \mathrm{II} \mathrm{L} / \mathrm{min}[0.9 \%]) ; \mathrm{NSD} \text { in } \mathrm{W}_{\text {max }} \text { from } \\
\text { first to second day }(\Delta \mathrm{I} \mathrm{W}[1.5 \%])\end{array}$ \\
\hline Cox et $\mathrm{al}^{49}$ & II (8) & Individually listed in paper & First versus second test & $\begin{array}{l}\text { NSD in peak } \mathrm{VO}_{2} \text { from first to second day } \\
(\Delta 0.04 \mathrm{~L} / \mathrm{min}[2.0 \%]) ; \mathrm{NSD} \text { in } \mathrm{W}_{\max } \text { from } \\
\text { first to second day }(\Delta \mathrm{I} \mathrm{W}[0.6 \%])\end{array}$ \\
\hline Mathur et al ${ }^{50}$ & $8(6)$ & $0.69 \pm 0.16(N R)$ & First versus second test & $\begin{array}{l}\text { Numerical increase in peak } \mathrm{VO}_{2} \text { from first } \\
\text { to second test }(\Delta 0.8 \mathrm{~mL} / \mathrm{min} / \mathrm{kg}[6.8 \%] \text {; } \\
\text { statistical test } \mathrm{NR})\end{array}$ \\
\hline Poulain et $\mathrm{al}^{30}$ & $10(N R)$ & Moderate COPD & $\begin{array}{l}\text { Familiarization then first } \\
\text { versus second test }\end{array}$ & $\begin{array}{l}\mathrm{NSD} \text { in \%-predicted peak } \mathrm{VO}_{2} \text { from first to } \\
\left.\text { second day ( } \Delta 2.5 \% \text {-predicted } \mathrm{VO}_{2}[3.9 \%]\right) ; \\
\mathrm{NSD} \text { in } \mathrm{W}_{\max } \text { from first to second day }(\Delta \mathrm{I} \\
\mathrm{W}[\mathrm{I} .3 \%])\end{array}$ \\
\hline Swinburn et $\mathrm{al}^{41}$ & $17(6)$ & $0.77 \pm 0.30(N R)$ & $\begin{array}{l}\text { First versus second } \\
\text { versus third versus } \\
\text { fourth test }\end{array}$ & $\begin{array}{l}\text { Progressive and significant increases in } \\
\text { duration from first to fourth day }(29 \% \text {; } \\
\text { baseline values } N R)\left(\mathrm{VO}_{2} / \mathrm{W}_{\max } \mathrm{NR}\right)\end{array}$ \\
\hline \multicolumn{5}{|c|}{ Endurance cycle ergometer test } \\
\hline \multicolumn{5}{|c|}{ Reproducibility ${ }^{\mathrm{b}}$} \\
\hline van't Hul et $\mathrm{al}^{51}$ & $60(46)$ & Moderate/severe COPD & First versus second test & $\begin{array}{l}\text { NSD in duration from first to second test } \\
(\Delta-12 \mathrm{~s} \text { [approximately }-4.4 \%])(\text { ICC } \\
=0.85)\end{array}$ \\
\hline
\end{tabular}

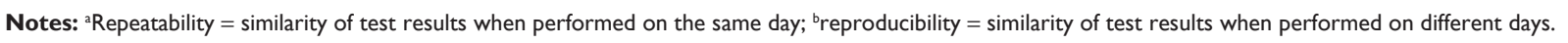

Abbreviations: $\mathrm{FEV}_{1}$, forced expiratory volume (L) in I second; ICC, intra-class correlation coefficient; NR, not reported; NSD, no significant difference; SD, standard deviation; $\mathrm{VO}_{2}$, oxygen consumption; $\mathrm{W}_{\max }$, maximum workload; $\mathrm{W}$, watts; min, minutes; s, time in seconds.

was no significant difference between the second and third tests..$^{18,20,21}$ The only study that presented intra-class correlation coefficients (ICCs) for repeated 6MWTs on the same day reported excellent repeatability (ICC $=0.94$ ), but also observed that the second test was significantly higher. ${ }^{16}$ For the 12MWT, the distance achieved was reported to be repeatable in the only study in which patients were retested on the same day. ${ }^{22}$ Equivocal results were reported for the repeatability of the ISWT by three studies; ${ }^{18,21,23}$ one found that the distance was repeatable after familiarization, ${ }^{18}$ but the other two reported poor repeatability even after familiarization (Table 2). ${ }^{21,23}$ For the ESWT, exercise duration was reported to be repeatable in the two studies in which patients were retested on the same day. ${ }^{23,24}$ One study reported that peak $\mathrm{VO}_{2}$ and $\mathrm{W}_{\max }$ were repeatable for the ICET (Table 3). ${ }^{25}$ No repeatability data were found for the ECET, ITT, or ETT.
Reproducibility of the 6MWT was assessed in 12 studies, ${ }^{17,18,26-35}$ six of which reported that distances achieved in the 6MWT demonstrated good reproducibility between the first and second tests (Table 1). ${ }^{17,27,28,32,35}$ Of two studies presenting reproducibility results from three $6 \mathrm{MWTs},{ }^{18,28}$ only one reported reproducibility between the second and third tests. ${ }^{28}$ Two further studies reported results of tests after familiarization; ${ }^{26,30}$ only one found 6MWT results to be reproducible. ${ }^{30}$ The only study presenting ICC data between the first and second 6MWT performance showed high reproducibility ( $\mathrm{ICC}=0.88$ ), but also that there was a significant increase in distance in the second 6MWT ${ }^{33}$ Reproducibility of the 12MWT was assessed in seven studies. ${ }^{22,36-41}$ Five of these presented the results of three or more tests, and reported that the 12MWT distance increased significantly from the first to the second test: $;^{36,37,39-41}$ one of these studies reported that in a subset of patients who readily experienced 
exercise-induced hypoxia, the 12MWT distance did not significantly change from the first to the second to the third test. ${ }^{36}$ Two additional studies, in which there had been prior familiarization with the test, reported no significant change in 12MWT distance between subsequent first and second tests. ${ }^{22,38}$ For the ISWT, five studies presented data assessing reproducibility: from the first to the second test with prior familiarization, ${ }^{42,43}$ from the first to the second test without prior familiarization, ${ }^{44,45}$ and from the second to the third test without prior familiarization (Table 2). ${ }^{18}$ Two further studies evaluating the ESWT reported reproducibility (either from the first to the second test with prior familiarization, ${ }^{46}$ or from the second to the third test without familiarization). ${ }^{47}$ Good reproducibility of the ICET from the first to the second test was reported by four studies both with ${ }^{30}$ and without prior familiarization (Table 3). ${ }^{25,48,49}$ Two further studies reported an increase in ICET duration from the first to the second test with no familiarization, ${ }^{41,50}$ with one of these studies reporting progressive increases in ICET duration from the first through to the fourth test. ${ }^{41}$ In the only study reporting data for the ECET, duration was found to have excellent reproducibility $(\mathrm{ICC}=0.85) .{ }^{51}$ Reproducibility was also found to be excellent in the only study reporting such data for the ETT (no significant increases from the first to the second test, ICC $=0.85),{ }^{52}$ but less so for the ITT (increased peak $\mathrm{VO}_{2}$ from the first to the second test, statistical test not reported). ${ }^{50}$

Several studies were identified that compared the repeatability and/or reproducibility of two or more exercise tests. One study observed that repeatability for the 6MWT and the ISWT was comparable, but that the ISWT was more reproducible. ${ }^{18}$ However, another study showed that the ISWT was more repeatable than the $6 \mathrm{MWT} .{ }^{21}$ One study reported that both the 6MWT and the ICET were reproducible. ${ }^{30}$ The ESWT was reported to be more repeatable than the ISWT in one study, when measured in two sessions before and two sessions after pulmonary rehabilitation. ${ }^{23}$ In another study, both 12MWT distance and ICET performance were found to increase significantly and progressively over four tests; the ICET was found to have no obvious advantages over the 12MWT when assessing exercise performance. ${ }^{41}$ The final study to report reproducibility of more than one test reported that peak $\mathrm{VO}_{2}$ increased from test 1 to test 2 in both the ICET and the ITT; however, the authors did not report the statistical tests used..$^{50}$ Three studies ${ }^{18,28,30}$ were found that compared the reproducibility of two or more exercise tests. Of these, two reported that the $6 \mathrm{MWT}$ was found to have similar reproducibility to the ISWT ${ }^{18}$ and the ICET. ${ }^{30}$

\section{Studies comparing responses to interventions among exercise tests}

In total, 23 studies were identified that compared responses of two or more exercise tests after one of the following interventions: pulmonary rehabilitation (16 studies), ${ }^{23,47,53-66}$ administration of bronchodilators (six studies), ${ }^{14,18,67-70}$ and lung-volume reduction surgery (one study) ${ }^{71}$ (Table 4). Of the 16 studies that assessed pulmonary rehabilitation in patients with COPD, the most commonly assessed test was the $6 \mathrm{MWT}$, which was reported by eleven studies. ${ }^{53-55,57-59,61,63-66}$

Two studies compared the response to the 6MWT and ITT after pulmonary rehabilitation; both reported significant increases in 6MWT distance and ITT performance (peak $\mathrm{VO}_{2}{ }^{53}$ and work-level completed). ${ }^{57}$ However, the latter study did not observe a significant response in peak $\mathrm{VO}_{2}$ during the ITT after pulmonary rehabilitation. ${ }^{57}$ One further study assessed the 6MWT and ITT during nutritional supplementation and placebo, and reported that the 6MWT distance was sensitive to pulmonary rehabilitation ( $>$ MCID); but these authors did not present peak $\mathrm{VO}_{2}$ or $\mathrm{W}_{\text {max }}$ data for the ITT. ${ }^{54}$ Another study assessed the 6MWT, ETT, and ITT, and found that both the ETT and the ITT were sensitive to pulmonary rehabilitation, whereas the 6MWT was not (again, the authors did not report peak $\mathrm{VO}_{2}$ or $\mathrm{W}_{\max }$ data for the ITT). ${ }^{58}$ Several further studies reported equivocal findings when comparing the 6MWT with the ICET ${ }^{55,63-65}$ after pulmonary rehabilitation. All three studies comparing the ECET with the 6MWT found the ECET to be more responsive to pulmonary rehabilitation. ${ }^{63,65,66}$ One study assessing responses to pulmonary rehabilitation reported similar sensitivities for the 6MWT and the ISWT, with both giving responses that exceeded the MCID. ${ }^{61}$ All four studies assessing the sensitivity of the ISWT and the ESWT to pulmonary rehabilitation reported a significant improvement in performance for both tests; ${ }^{23,47,60,62}$ however, in all four studies the response of the ESWT was greater and in two the ISWT response did not reach the MCID. ${ }^{23,47}$ An additional study suggested that although both tests showed a significant response that was above the MCID, the ESWT was more responsive to pulmonary rehabilitation than the $6 \mathrm{MWT} .{ }^{59}$ Equivocal sensitivity was observed in response to pulmonary rehabilitation when using the $12 \mathrm{MWT}$ and the ICET. ${ }^{56}$

Of the six studies comparing the responses of two or more exercise tests to bronchodilator therapy, ${ }^{14,18,67-70}$ one reported the 6MWT to be more responsive to pharmacological intervention than the $12 \mathrm{MWT}^{67}$ and one reported the $6 \mathrm{MWT}$ to be more responsive to pharmacological intervention 


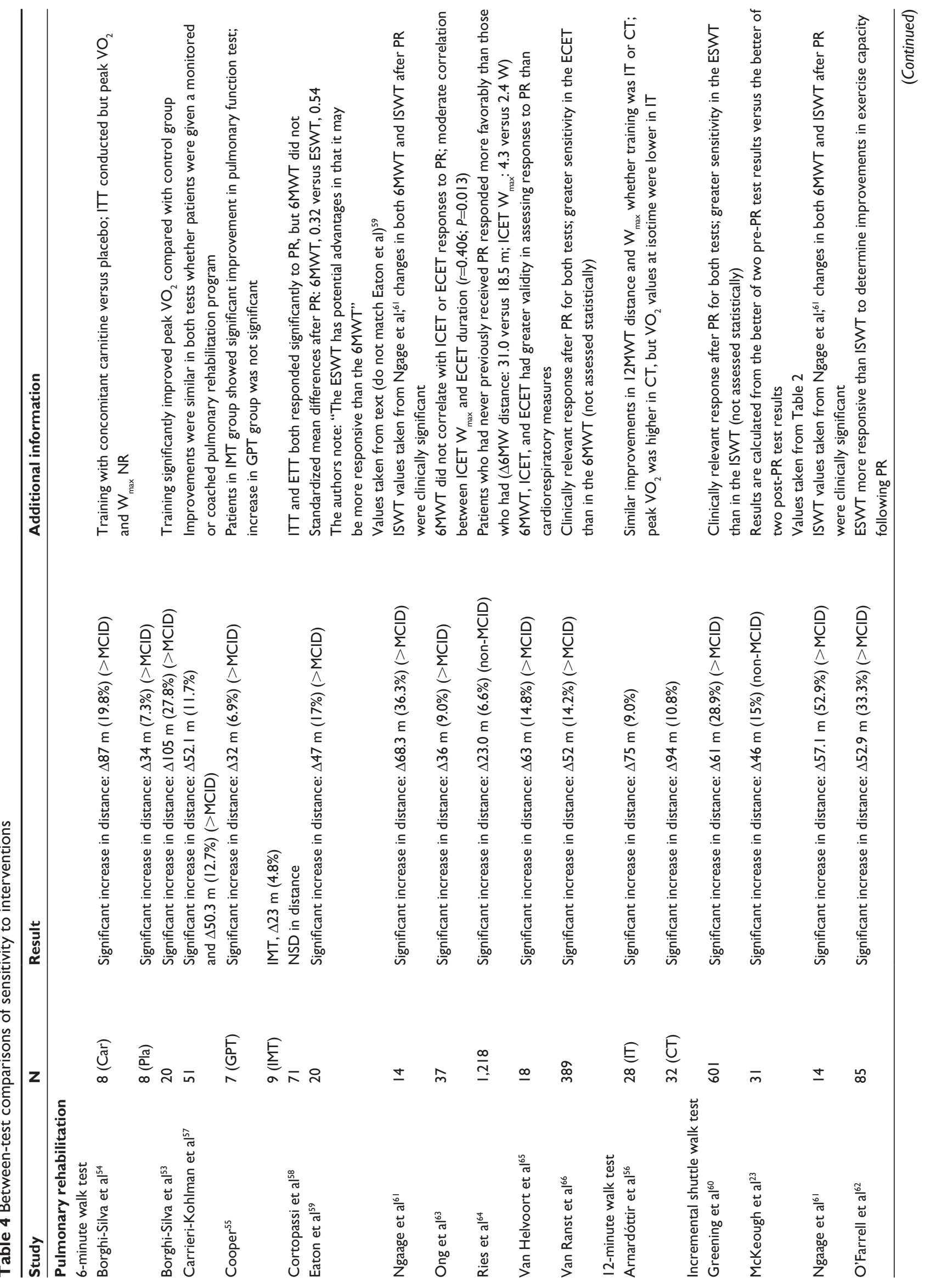




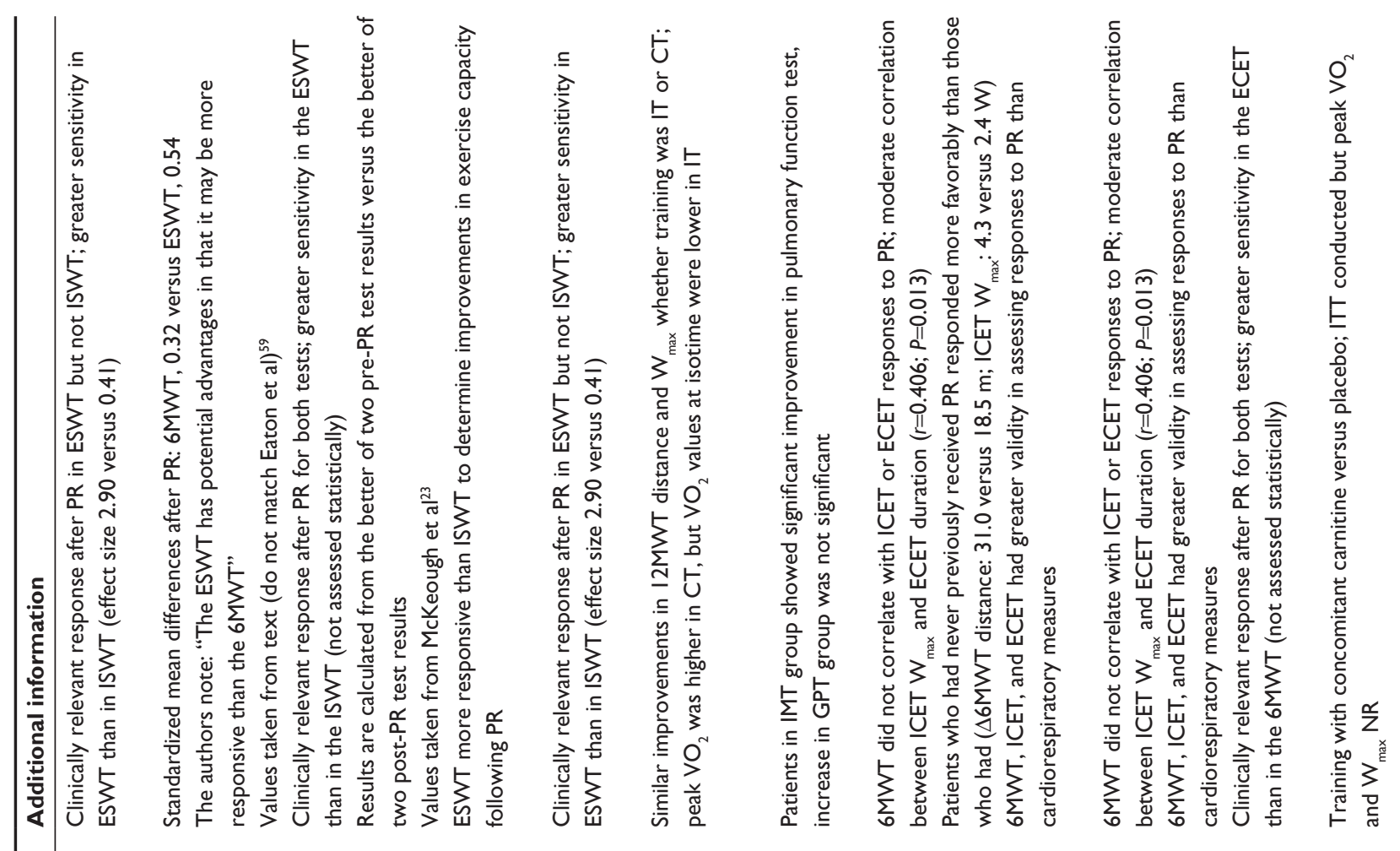

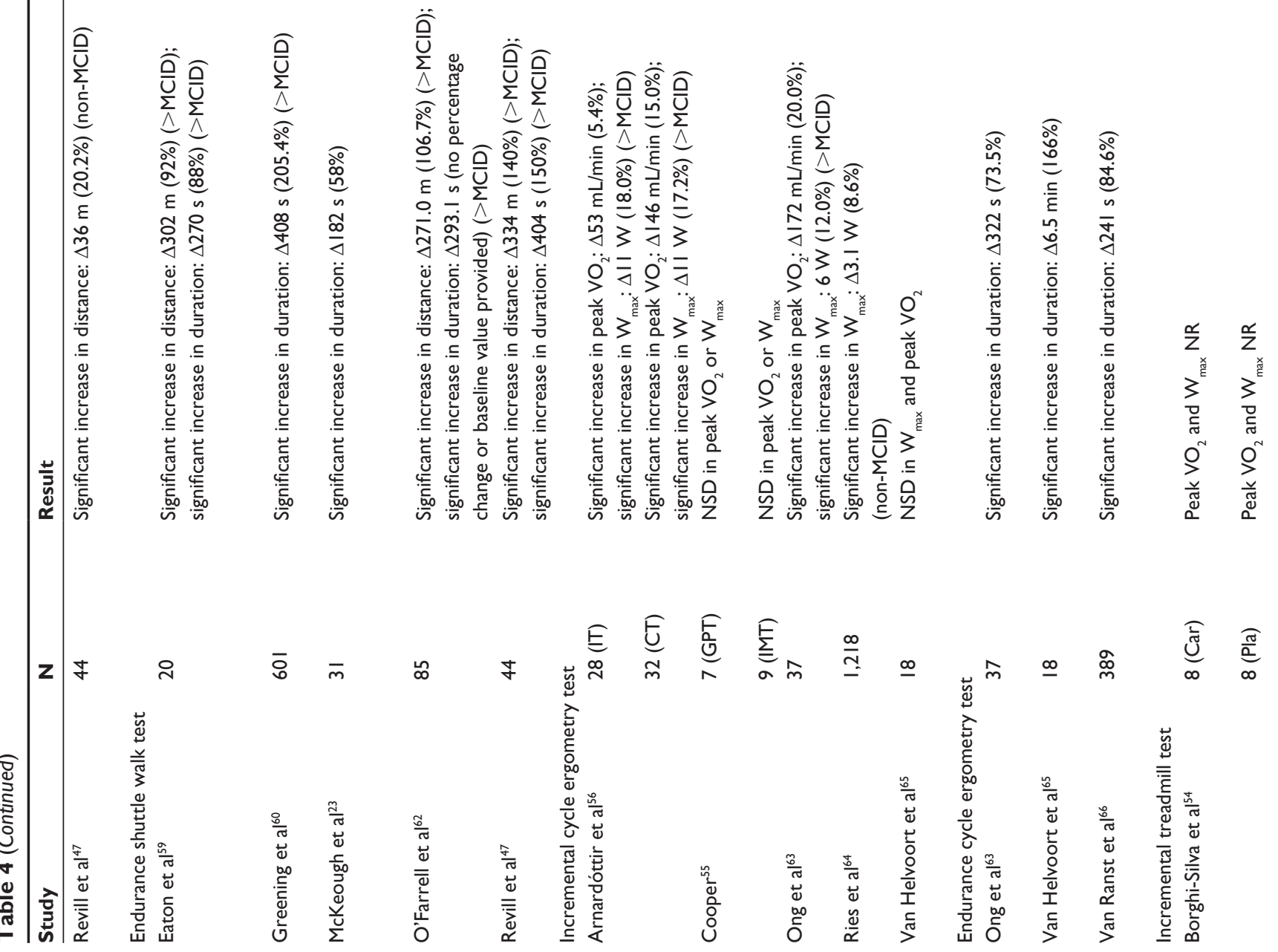



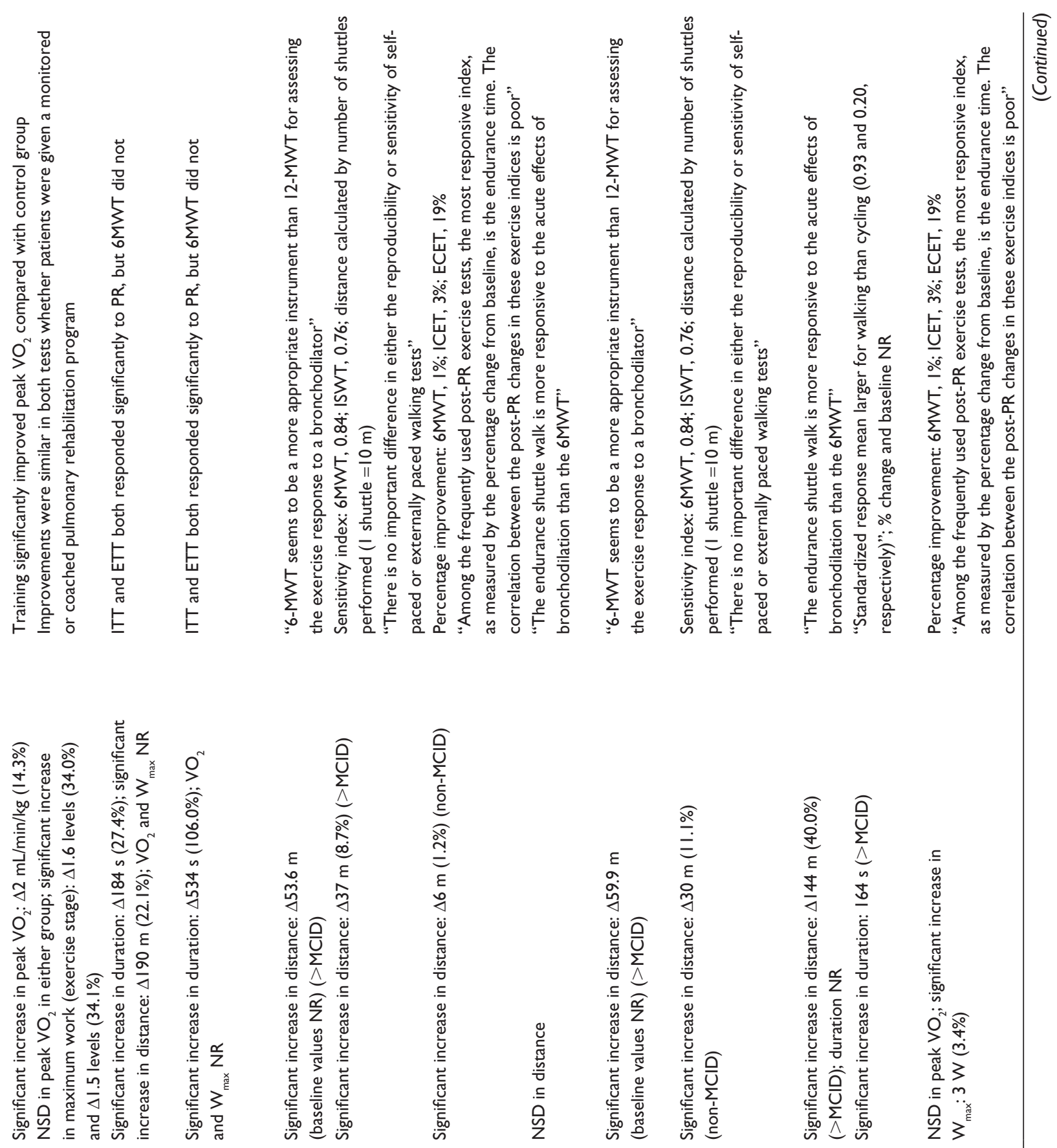

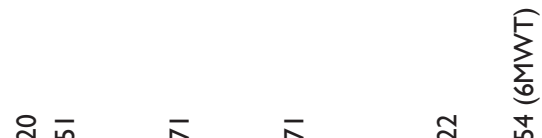
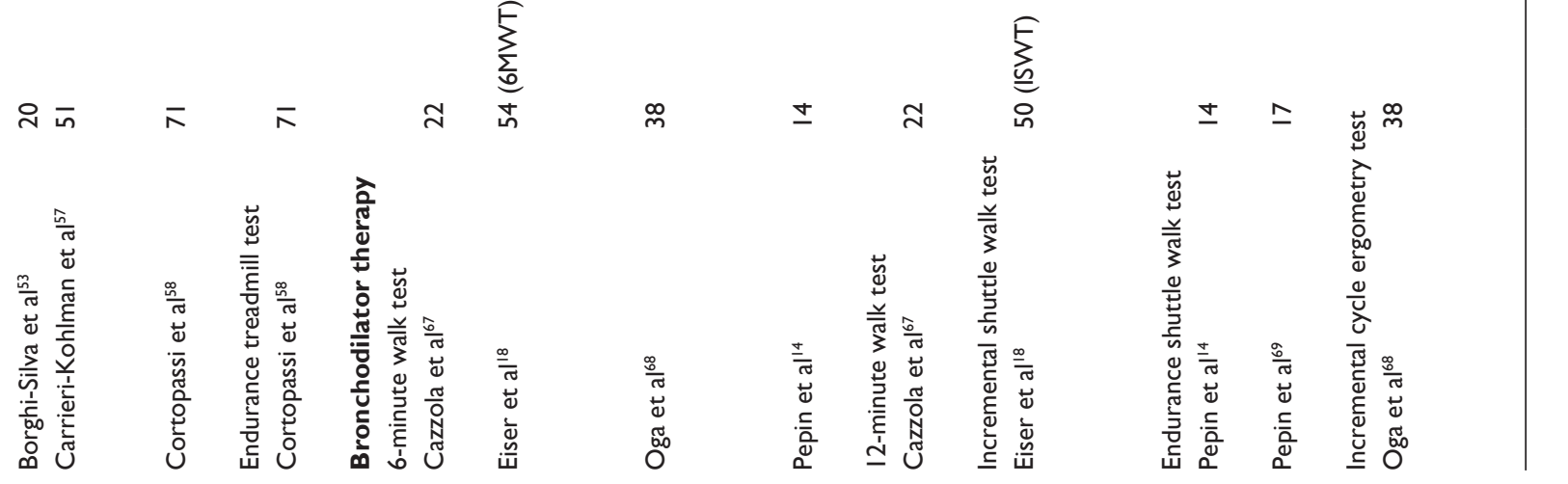


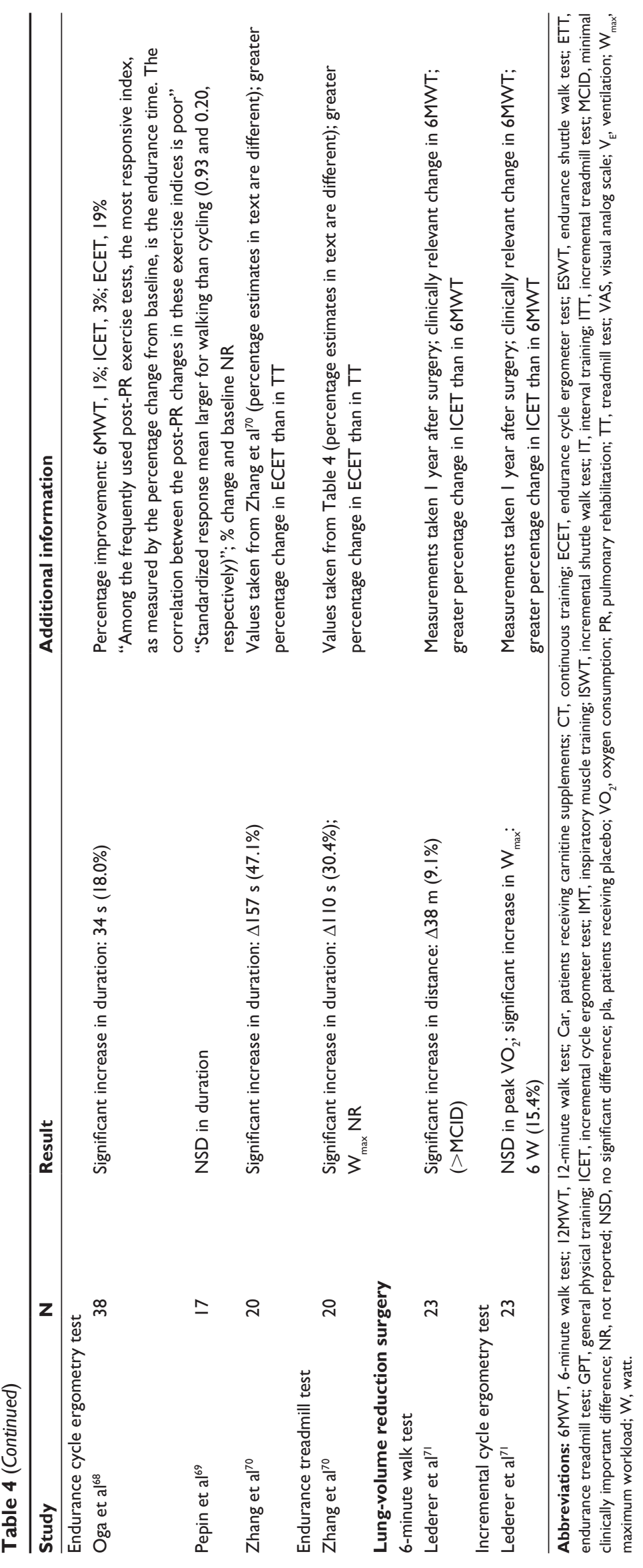


than the ISWT. ${ }^{18}$ The standardized (percentage) increase in response to the ECET was higher than that of either the $6 \mathrm{MWT}$ or the ICET in one study, ${ }^{68}$ and higher than that of the ETT in another. ${ }^{70}$ One study reported the response of the ESWT to bronchodilation to be greater than that of the $6 \mathrm{MWT}^{14}$ and one study reported the response of the ESWT to bronchodilation to be greater than that of the ECET. ${ }^{69}$

Finally, one study assessed exercise test performance 1 year after lung-volume reduction surgery, and reported a $9.1 \%$ increase in 6MWT distance and a $15.4 \%$ increase in ICET $\mathrm{W}_{\text {max }}$, but noted that ICET peak $\mathrm{VO}_{2}$ did not increase significantly. ${ }^{71}$

\section{Minimal clinically important differences in responses to interventions}

MCIDs have been thus far ascertained for the 6MWT (26 meters), ${ }^{12}$ the ISWT (48 meters), ${ }^{13}$ the ESWT (45 seconds-85 seconds or 60 meters-115 meters [MCID calculated after bronchodilatory intervention]), ${ }^{72}$ and the ICET (4 watts). ${ }^{12}$ Of the eleven studies assessing the 6MWT in response to pulmonary rehabilitation, nine reported an increase in excess of the recognized MCID, ${ }^{53-55,57,59,61,63,65,66}$ with another reporting a significant increase in distance of less than the $\mathrm{MCID}^{64}$ (the remaining study reported no significant change in 6MWT distance after pulmonary rehabilitation $^{58}$ ); these increases ranged in magnitude from $4.8 \%$ to $36.3 \%$. Five studies reported a significant response of the ISWT to pulmonary rehabilitation ranging from $15.0 \%$ to $52.9 \%,{ }^{23,47,60-62}$ with three finding that the distance observed reached the MCID. ${ }^{60-62}$ All five studies assessing the sensitivity of the ESWT to pulmonary rehabilitation reported that distance and/or duration increased in excess of the MCID (increases ranged from $88.0 \%$ to $205.4 \%$ when expressed as time [seconds]; ${ }^{23,47,59,60,62}$ and from $92.0 \%$ to $140.0 \%$ when expressed as distance [meters]). ${ }^{47,59,62}$ Of five studies assessing the ICET before and after pulmonary rehabilitation, ${ }^{55,56,63-65}$ two reported $\mathrm{W}_{\text {max }}$ responses in excess of the $\mathrm{MCID},{ }^{56,63}$ and another reported significant changes in $\mathrm{W}_{\text {max }}$ that did not reach the MCID ${ }^{64}$ (the increased ICET performance observed across these studies ranged from 5.4\% to $20.0 \%$ for peak $\mathrm{VO}_{2}$ and $8.6 \%$ to $18.0 \%$ for $\mathrm{W}_{\max }$ ). The two remaining studies did not observe a significant change in ICET peak $\mathrm{VO}_{2}$ or $\mathrm{W}_{\text {max }}$ after pulmonary rehabilitation. ${ }^{55,65}$ All three studies reporting the response of the ECET to pulmonary rehabilitation observed significant increases in duration (ranging from $73.5 \%$ to $166.0 \%$ ). ${ }^{63,65,66}$ Four studies assessed the ITT before and after pulmonary rehabilitation; two did not present data for either peak $\mathrm{VO}_{2}$ or $\mathrm{W}_{\max }{ }^{54,58}$ Of the remaining two studies, one reported a significant increase in peak $\mathrm{VO}_{2}$ of $14.3 \%,{ }^{53}$ while the other found no significant increase in peak $\mathrm{VO}_{2}$ after pulmonary rehabilitation. ${ }^{58}$ The only study assessing the ETT before and after pulmonary rehabilitation reported significant increases in duration (27.4\%) and distance $(22.1 \%){ }^{58}$

Of the four studies assessing the $6 \mathrm{MWT}$ before and after bronchodilator therapy, two reported improvements in distance that exceeded the MCID (one found an increase in 6MWT distance of $8.7 \%,{ }^{18}$ the other reported a higher absolute distance increase [53.6 meters], but did not present baseline values; therefore the percentage increase cannot be calculated $\left.{ }^{67}\right)$. The third study reported a small $(1.2 \%)$ but significant increase in 6MWT distance, ${ }^{68}$ while the remaining study found no significant difference in 6MWT distance. ${ }^{14}$ One study found a significant increase in 12MWT distance after bronchodilation in excess of the MCID (59.9 meters), but did not provide baseline values. ${ }^{67}$ One study reported a significant increase in ISWT performance after bronchodilators (30 meters) that did not reach the MCID. ${ }^{18}$ Two studies reported significant increases in ESWT performance above the MCID, of 144 meters ${ }^{14}$ and 164 seconds, ${ }^{69}$ respectively. One study reported a small but significant improvement in ICET $\mathrm{W}_{\text {max }}$ of $3.4 \%$ after bronchodilator therapy, but noted that peak $\mathrm{VO}_{2}$ did not increase significantly. ${ }^{68}$ Three studies assessed ECET performance after bronchodilators; two found significant increases in duration of $18.0 \%{ }^{68}$ and $47.1 \%,{ }^{70}$ with the remaining study reporting no significant improvement in ECET duration. ${ }^{69}$

In the only study assessing lung-volume reduction surgery, a 6MWT improvement in excess of the MCID was seen; however, ICET improvements (whether peak $\mathrm{VO}_{2}$ or $\mathrm{W}_{\max }$ ) did not reach MCID. ${ }^{71}$

\section{Studies assessing within-test variations in protocol}

Eighteen studies were identified that assessed minor variations in protocol within a specific exercise test (Table 5). ${ }^{17,20,33,46,73-86}$ Variations (such as track environment or layout and the type of encouragement provided by the investigators to the patient) affected test outcomes (and consequently, their repeatability and reproducibility).

\section{Discussion}

A number of laboratory- and field-based exercise tests are used to assess the degree of functional impairment in patients with COPD. However, the choice of which test to use in clinical trials historically seems to have been made 
Table 5 Protocol variations reported to affect performance of exercise capacity test

\begin{tabular}{|c|c|c|}
\hline Test & Variation & Study \\
\hline \multirow[t]{11}{*}{ 6MWT } & Track layout & Sciurba et $\mathrm{al}^{33}$ \\
\hline & & Casas et $\mathrm{al}^{76}$ \\
\hline & & Bansal et $\mathrm{al}^{17}$ \\
\hline & Supplemental oxygen provided & Revill et al ${ }^{46}$ \\
\hline & & Borghi-Silva et a $7^{75}$ \\
\hline & & Davidson et a $\left.\right|^{77}$ \\
\hline & & Ozalevli et al ${ }^{83}$ \\
\hline & Corridor versus treadmill & Stevens et $\mathrm{al}^{20}$ \\
\hline & Indoor versus outdoor environment & de Almeida et $\mathrm{al}^{78}$ \\
\hline & Wheeled walker support provided & Honeyman et $\mathrm{al}^{80}$ \\
\hline & Verbal encouragement provided & Crisafulli et $\mathrm{al}^{73}$ \\
\hline I2MWT & Corridor versus treadmill & Swerts et $\mathrm{a}^{86}$ \\
\hline \multirow[t]{2}{*}{ ISWT } & Verbal encouragement & Rosa et $\mathrm{a}^{84}$ \\
\hline & Supplemental oxygen provided & Sandland et al ${ }^{85}$ \\
\hline ESWT & Supplemental oxygen provided & Sandland et $\mathrm{al}^{85}$ \\
\hline \multirow[t]{2}{*}{ ICET } & Incremental workload gradient used & Benzo et $\mathrm{al}^{74}$ \\
\hline & & Miyahara et al ${ }^{82}$ \\
\hline ECET & Supplemental oxygen provided & Dean et $\mathrm{al}^{79}$ \\
\hline ITT & Incremental workload gradient used & Hsia et $\mathrm{al}^{81}$ \\
\hline
\end{tabular}

Abbreviations: 6MWT, 6-minute walk test; 12MWT, 12-minute walk test; ECET, endurance cycle ergometer test; ESWT, endurance shuttle walk test; ICET, incremental cycle ergometer test; ISWT, incremental shuttle walk test, ITT, incremental treadmill test.

on a practical basis (tests such as the 6MWT and 12MWT require little time, organization, or equipment), or without necessarily taking into account how representative the exercise modality used is to activities of daily living for these patients (eg, cycling tests) or the likely impact of the intervention on the outcome of the test. Equally there are few data describing the relative merits of these tests employed simultaneously to evaluate interventions such as rehabilitation and bronchodilator therapy. Results from this systematic review indicate that there is an extensive body of published literature regarding the performance of the eight exercise tests that are widely used.

Repeatability data were found for only the 6MWT, 12MWT, ISWT, ESWT, and ICET. As could be anticipated, we did not identify studies assessing the repeatability of the ECET, ITT, or ETT; these studies test to exhaustion and would be impractical for patients with COPD to perform repeatedly on the same day. Of those reported, the 6MWT was by far the most thoroughly assessed. This may reflect its simplicity and relevance to daily life. ${ }^{87}$ However, a substantial proportion of the reported data does not explicitly support 6MWT repeatability. Some studies suggested that the ISWT was more repeatable ${ }^{21}$ and reproducible ${ }^{18}$ than the $6 \mathrm{MWT}$, while another found that the ESWT was, in turn, more repeatable than the ISWT. ${ }^{23}$ The comparative results of exercise tests are inconsistent. Furthermore, there are only very limited data to support the repeatability and/or reproducibility of all cycle tests and treadmill tests. Repeatability and reproducibility were generally improved with familiarization in all types of test. Although this review assesses the influence of protocol variations, it is possible that some studies in which variations were not the primary focus may not have been identified. However, it is clear that even in ostensibly identical tests (eg, two studies reporting the 6MWT), responses can be significantly affected by subtle variations in track layout or environment, or by encouragement from the researchers conducting the test.

When studies reporting the sensitivity of two or more exercise tests to therapeutic intervention were reviewed, there was no consistent evidence supporting the use of one test over any other. Nine of the eleven studies assessing the 6MWT after pulmonary rehabilitation, ${ }^{53-55,57,59,61,63,65,66}$ two of the four studies assessing 6MWT after bronchodilators, ${ }^{18,67}$ and the only study assessing the 6MWT after lung-volume reduction surgery ${ }^{71}$ all reported distance improvements greater than the MCID. Additionally, three of the five studies assessing ISWT $^{60-62}$ and all five of the studies assessing ESWT after pulmonary rehabilitation ${ }^{23,47,59,60,62}$ reported distance improvements greater than the MCID. Performance improvements were also observed to be in excess of the MCID in the only two studies assessing the ESWT following bronchodilator therapy; $;^{14,69}$ this was therefore the only exercise test reported by multiple papers that consistently responded to therapeutic interventions to a clinically relevant degree. It must be considered that these exercise tests have differing physiological demands, and it may be that the benefits of each intervention are measured differently by each test. However, limited data for bronchodilator therapy and lung-volume reduction surgery make it difficult to identify any obvious differences in the responses of tests to these interventions.

The review has several limitations that must be acknowledged. As well as identifying whether or not test responses have exceeded the MCID, we have also reported percentage changes in exercise test performance whenever possible to enable a very crude comparison of test outcomes recorded in different units. However, we are aware that the validity of this comparison relies on a direct relationship between these test outcomes, which is unlikely to be true: a large percentage change in one test result may not be equivalent to a large percentage change in another.

In an attempt to assess the validity of exercise tests in patients with COPD as comprehensively as possible, we have collated data from studies that have used various definitions of COPD, which include distinct subcategories 
such as emphysema and chronic bronchitis, and that have employed diverse methods of assessing diagnosis and severity. Moreover, the study designs included are very diverse. These issues make meaningful meta-analysis difficult. We have, however, tried to provide the ranges of responses (both absolute and percentage changes) when possible, to provide an indication of the magnitude of exercise test responses. A further consequence of the comprehensive nature of this review is that the sample sizes of the identified studies vary widely. For this reason, we have included study sample sizes in our tables.

Decisions regarding which test to use are also influenced by the practicalities of routine clinical practice. It is reasonable to assume that walking is more representative of daily life than cycling for patients with COPD. Furthermore, given the equivocal evidence for the use of the ESWT over the ISWT, clinicians may wish to consider that the ESWT requires a prior "workload setting" ISWT to be performed by the patient, requiring additional time and resource considerations. Any test of exercise capacity should be highly repeatable and reproducible and also should be able to detect changes in performance after interventions aiming to improve exercise capacity.

\section{Conclusion}

This review of the published literature has found good evidence to support the repeatability and reproducibility of all tests, particularly the 6MWT, as long as a prior familiarization is conducted. There is consistent evidence to suggest that the ESWT is highly sensitive to therapeutic intervention. Sensitivity data that are available for other tests are largely inconsistent, and the 6MWT and ISWT appear to be less sensitive to intervention than the ESWT and ICET. These factors, allied to practical aspects, must be considered when planning interventional trials.

\section{Author contributions}

All authors contributed to the conception and design of the study, the analysis and interpretation of data, and revision of the manuscript. All authors approved the final version of the manuscript for publication.

\section{Acknowledgments}

The study was funded by GlaxoSmithKline UK. Writing support was provided by Martin Bell of Oxford PharmaGenesis $^{\text {TM }}$ Ltd, funded by GlaxoSmithKline UK. Georgina Meakin and Iain Fotheringham are employees of Oxford PharmaGenesis Ltd, which has received funding from
GlaxoSmithKline UK. Yogesh Suresh Punekar, John Riley, and Sarah Cockle are current employees of GlaxoSmithKline, Uxbridge, UK. Sally J Singh was involved with the development of the incremental shuttle walk test, and has served on advisory boards for GlaxoSmithKline. Sally J Singh was part funded by the National Institute for Health Research (NIHR) Collaboration for Leadership in Applied Health Research and Care East Midlands. Support was also provided by the NIHR Leicester Respiratory Biomedical Research Unit. The views expressed are those of the authors and not necessarily those of the National Health Service, the NIHR, or the Department of Health.

\section{Disclosure}

Other than the funding outlined in the "Acknowledgments" section, the authors declare no conflicts of interest in this work.

\section{References}

1. Lopez AD, Shibuya K, Rao C, et al. Chronic obstructive pulmonary disease: current burden and future projections. Eur Respir J. 2006; 27(2):397-412.

2. Halbert RJ, Natoli JL, Gano A, Badamgarav E, Buist AS, Mannino DM. Global burden of COPD: systematic review and meta-analysis. Eur Respir J. 2006;28(3):523-532.

3. Mathers CD, Loncar D. Projections of global mortality and burden of disease from 2002 to 2030. PLoS Med. 2006;3(11):e442.

4. American Thoracic Society/European Respiratory Society Task Force. Standards for the Diagnosis and Management of Patients with COPD [Internet]. Version 1.2. New York: American Thoracic Society; 2004 [updated September 8, 2005]. Available from: http://www.thoracic.org/ go/copd-guidelines/. Accessed May 19, 2014.

5. Global Initiative for Chronic Obstructive Lung Disease (GOLD) Global Strategy for the Diagnosis, Management and Prevention of COPD [Internet]. GOLD; 2014. Available from: http://www.goldcopd. org/uploads/users/files/GOLD_Report_2014_Jun11.pdf. Accessed September 12, 2014

6. Corhay JL, Dang DN, Van Cauwenberge H, Louis R. Pulmonary rehabilitation and COPD: providing patients a good environment for optimizing therapy. Int J Chron Obstruct Pulmon Dis. 2014;9:27-39.

7. Jones P, Miravitlles M, van der Molen T, Kulich K. Beyond FEV(1) in COPD: a review of patient-reported outcomes and their measurement. Int J Chron Obstruct Pulmon Dis. 2012;7:697-709.

8. Cooper CB. The connection between chronic obstructive pulmonary disease symptoms and hyperinflation and its impact on exercise and function. Am J Med. 2006;119(10 Suppl 1):21-31.

9. Jones PW. Issues concerning health-related quality of life in COPD Chest. 1995;107(Suppl 5):187S-193S.

10. Mahler DA, Harver A. A factor analysis of dyspnea ratings, respiratory muscle strength, and lung function in patients with chronic obstructive pulmonary disease. Am Rev Respir Dis. 1992;145(2 Pt 1):467-470.

11. National Institute for Health and Clinical Excellence (NICE). Management of chronic obstructive pulmonary disease in adults in primary and secondary care (partial update). NICE guideline CG101. London: NICE; 2010. Available from: http://guidance.nice.org.uk/ cg101. Accessed May 19, 2014.

12. Puhan MA, Chandra D, Mosenifar Z, et al. The minimal important difference of exercise tests in severe COPD. Eur Respir J. 2011;37(4): 784-790. 
13. Singh SJ, Jones PW, Evans R, Morgan MD. Minimum clinically important improvement for the incremental shuttle walking test. Thorax. 2008;63(9):775-777.

14. Pepin V, Brodeur J, Lacasse Y, et al. Six-minute walking versus shuttle walking: responsiveness to bronchodilation in chronic obstructive pulmonary disease. Thorax. 2007;62(4):291-298.

15. Moher D, Liberati A, Tetzlaff J, Altman DG, Group P. Preferred reporting items for systematic reviews and meta-analyses: the PRISMA statement. BMJ. 2009;339:b2535.

16. Andersson M, Moberg L, Svantesson U, Sundbom A, Johansson H, Emtner M. Measuring walking speed in COPD: Test-retest reliability of the 30-metre walk test and comparison with the 6-minute walk test. Prim Care Respir J. 2011;20(4):434-440.

17. Bansal V, Hill K, Dolmage TE, Brooks D, Woon LJ, Goldstein RS. Modifying track layout from straight to circular has a modest effect on the 6-min walk distance. Chest. 2008;133(5):1155-1160.

18. Eiser N, Willsher D, Dore CJ. Reliability, repeatability and sensitivity to change of externally and self-paced walking tests in COPD patients. Respir Med. 2003;97(4):407-414.

19. Jenkins S, Cecins NM. Six-minute walk test in pulmonary rehabilitation: do all patients need a practice test? Respirology. 2010;15(8): 1192-1196

20. Stevens D, Elpern E, Sharma K, Szidon P, Ankin M, Kesten S. Comparison of hallway and treadmill six-minute walk tests. Am J Respir Crit Care Med. 1999;160(5 Pt 1):1540-1543.

21. Vagaggini B, Taccola M, Severino S, et al. Shuttle walking test and 6-minute walking test induce a similar cardiorespiratory performance in patients recovering from an acute exacerbation of chronic obstructive pulmonary disease. Respiration. 2003;70(6):579-584.

22. O'Reilly JF, Shaylor JM, Fromings KM, Harrison BD. The use of the 12 minute walking test in assessing the effect of oral steroid therapy in patients with chronic airways obstruction. Br J Dis Chest. 1982;76(4):374-382.

23. McKeough ZJ, Leung RW, Alison JA. Shuttle walk tests as outcome measures: Are two incremental shuttle walk tests and two endurance shuttle walk tests necessary? Am J Phys Med Rehabil. 2011;90(1):35-39.

24. Revill SM, Williams J, Sewell L, Collier R, Singh SJ. Within-day repeatability of the endurance shuttle walk test. Physiotherapy. 2009;95(2):140-143.

25. Brown SE, Fischer CE, Stansbury DW, Light RW. Reproducibility of VO2max in patients with chronic air-flow obstruction. Am Rev Respir Dis. 1985;131(3):435-438.

26. Behnke M, Wewel AR, Kirsten D, Jorres RA, Magnussen H. Exercise training raises daily activity stronger than predicted from exercise capacity in patients with COPD. Respir Med. 2005;99(6):711-717.

27. Brooks D, Solway S, Weinacht K, Wang D, Thomas S. Comparison between an indoor and an outdoor 6-minute walk test among individuals with chronic obstructive pulmonary disease. Arch Phys Med Rehabil. 2003;84(6):873-876.

28. Chatterjee AB, Rissmiller RW, Meade K, et al. Reproducibility of the 6-minute walk test for ambulatory oxygen prescription. Respiration. 2010;79(2):121-127.

29. Kozu R, Jenkins S, Senjyu H, Mukae H, Sakamoto N, Kohno S. Peak power estimated from 6-minute walk distance in Asian patients with idiopathic pulmonary fibrosis and chronic obstructive pulmonary disease. Respirology. 2010;15(4):706-713.

30. Poulain M, Durand F, Palomba B, et al. 6-minute walk testing is more sensitive than maximal incremental cycle testing for detecting oxygen desaturation in patients with COPD. Chest. 2003;123(5): 1401-1407.

31. Rejeski WJ, Foley KO, Woodard CM, Zaccaro DJ, Berry MJ. Evaluating and understanding performance testing in COPD patients. $J$ Cardiopulm Rehabil. 2000;20(2):79-88.

32. Roomi J, Johnson MM, Waters K, Yohannes A, Helm A, Connolly MJ. Respiratory rehabilitation, exercise capacity and quality of life in chronic airways disease in old age. Age Ageing. 1996;25(1):12-16.
33. Sciurba F, Criner GJ, Lee SM, et al. Six-minute walk distance in chronic obstructive pulmonary disease: reproducibility and effect of walking course layout and length. Am J Respir Crit Care Med. 2003;167(11):1522-1527

34. Spencer LM, Alison JA, McKeough ZJ. Six-minute walk test as an outcome measure: are two six-minute walk tests necessary immediately after pulmonary rehabilitation and at three-month follow-up? Am J Phys Med Rehabil. 2008;87(3):224-228.

35. Troosters T, Vilaro J, Rabinovich R, et al. Physiological responses to the 6-min walk test in patients with chronic obstructive pulmonary disease. Eur Respir J. 2002;20(3):564-569.

36. Arnardóttir RH, Sorensen S, Ringqvist I, Larsson K. No increase in walking distance on repeated tests in COPD patients with exerciseinduced hypoxaemia. Adv Physiother. 2007;9(4):161-168.

37. Beaumont A, Cockcroft A, Guz A. A self paced treadmill walking test for breathless patients. Thorax. 1985;40(6):459-464.

38. Berger R, Smith D. Effect on inhaled metaproterenol on exercise performance in patients with stable 'fixed' airway obstruction. Am Rev Respir Dis. 1988;138(3):624-629.

39. McGavin CR, Gupta SP, McHardy GJ. Twelve minute walking test for assessing disability in chronic bronchitis. BMJ. 1976;1(6013): 822-823.

40. Mungall IP, Hainsworth R. Assessment of respiratory function in patients with chronic obstructive airways disease. Thorax. 1979;34(2): 254-258.

41. Swinburn CR, Wakefield JM, Jones PW. Performance, ventilation, and oxygen consumption in three different types of exercise test in patients with chronic obstructive lung disease. Thorax. 1985;40(8):581-586.

42. Campo LA, Chilingaryan G, Berg K, Paradis B, Mazer B. Validity and reliability of the modified shuttle walk test in patients with chronic obstructive pulmonary disease. Arch Phys Med Rehabil. 2006;87(7): 918-922.

43. Perrault H, Baril J, Henophy S, Rycroft A, Bourbeau J, Maltais F. Paced-walk and step tests to assess exertional dyspnea in COPD. COPD. 2009;6(5):330-339.

44. Arnardóttir RH, Emtner M, Hedenstrom H, Larsson K, Boman G. Peak exercise capacity estimated from incremental shuttle walking test in patients with COPD: a methodological study. Respir Res. 2006;7(127).

45. Singh SJ, Morgan MD, Scott S, Walters D, Hardman AE. Development of a shuttle walking test of disability in patients with chronic airways obstruction. Thorax. 1992;47(12):1019-1024.

46. Revill SM, Noor MZ, Butcher G, Ward MJ. The endurance shuttle walk test: An alternative to the six-minute walk test for the assessment of ambulatory oxygen. Chron Respir Dis. 2010;7(4):239-245.

47. Revill SM, Morgan MD, Singh SJ, Williams J, Hardman AE. The endurance shuttle walk: a new field test for the assessment of endurance capacity in chronic obstructive pulmonary disease. Thorax. 1999;54(3):213-222.

48. Covey MK, Larson JL, Alex CG, Wirtz S, Langbein WE. Test-retest reliability of symptom-limited cycle ergometer tests in patients with chronic obstructive pulmonary disease. Nurs Res. 1999;48(1):9-19.

49. Cox NJ, Hendriks JC, Binkhorst RA, Folgering HT, van Herwaarden CL. Reproducibility of incremental maximal cycle ergometer tests in patients with mild to moderate obstructive lung diseases. Lung. 1989;167(2):129-133.

50. Mathur RS, Revill SM, Vara DD, Walton R, Morgan MD. Comparison of peak oxygen consumption during cycle and treadmill exercise in severe chronic obstructive pulmonary disease. Thorax. 1995;50(8): 829-833.

51. van't Hul A, Gosselink R, Kwakkel G. Constant-load cycle endurance performance test-retest reliability and validity in patients with COPD. J Cardiopulm Rehabil. 2003;23(2):143-150.

52. Cooper CB, Abrazado M, Legg D, Kesten S. Development and implementation of treadmill exercise testing protocols in COPD. Int J Chron Obstruct Pulmon Dis. 2010;5:375-385. 
53. Borghi-Silva A, Arena R, Castello V, et al. Aerobic exercise training improves autonomic nervous control in patients with COPD. Respir Med. 2009;103(10):1503-1510.

54. Borghi-Silva A, Baldissera V, Sampaio LM, et al. L-carnitine as an ergogenic aid for patients with chronic obstructive pulmonary disease submitted to whole-body and respiratory muscle training programs. Braz J Med Biol Res. 2006;39(4):465-474.

55. Cooper CB. Desensitization to dyspnea in COPD with specificity for exercise training mode. Int J Chron Obstruct Pulmon Dis. 2009;4:33-43.

56. Arnardóttir RH, Boman G, Larsson K, Hedenström H, Emtner M Interval training compared with continuous training in patients with COPD. Respir Med. 2007;101(6):1196-1204.

57. Carrieri-Kohlman V, Gormley JM, Douglas MK, Paul SM, Stulbarg MS. Exercise training decreases dyspnea and the distress and anxiety associated with it. Monitoring alone may be as effective as coaching. Chest. 1996;110(6):1526-1535

58. Cortopassi F, Castro AA, Porto EF, et al. Comprehensive exercise training improves ventilatory muscle function and reduces dyspnea perception in patients with COPD. Monaldi Arch Chest Dis. 2009;71(3):106-112.

59. Eaton T, Young P, Nicol K, Kolbe J. The endurance shuttle walking test: A responsive measure in pulmonary rehabilitation for COPD patients Chron Respir Dis. 2006;3(1):3-9.

60. Greening NJ, Evans RA, Williams JE, Green RH, Singh SJ, Steiner MC. Does body mass index influence the outcomes of a waking-based pulmonary rehabilitation programme in COPD? Chron Respir Dis. 2012;9(2):99-106.

61. Ngaage DL, Hasney K, Cowen ME. The functional impact of an individualized, graded, outpatient pulmonary rehabilitation in end-stage chronic obstructive pulmonary disease. Heart Lung. 2004;33(6):381-389.

62. O'Farrell R, Gargoum F, O'Connor B, et al. Comparison of incremental and endurance shuttle walk testing after pulmonary rehabilitation. $\mathrm{Am}$ J Resp Crit Care Med. 2011;183:Abs A2024.

63. Ong KC, Chong WF, Soh C, Earnest A. Comparison of different exercise tests in assessing outcomes of pulmonary rehabilitation. Respir Care. 2004;49(12):1498-1503.

64. Ries AL, Make BJ, Lee SM, et al. The effects of pulmonary rehabilitation in the National Emphysema Treatment Trial. Chest. 2005;128(6): 3799-3809.

65. Van Helvoort HA, De Boer RC, Van De Broek L, Dekhuijzen R, Heijdra YF. Exercises commonly used in rehabilitation of patients with chronic obstructive pulmonary disease: cardiopulmonary responses and effect over time. Arch Phys Med Rehabil. 2011;92(1):111-117.

66. Van Ranst D, Otten H, Meijer JW, van't Hul AJ. Outcome of pulmonary rehabilitation in COPD patients with severely impaired health status. Int J Chron Obstruct Pulmon Dis. 2011;6(1):647-657.

67. Cazzola M, Biscione GL, Pasqua F, et al. Use of 6-min and 12-min walking test for assessing the efficacy of formoterol in COPD. Respir Med. 2008;102(10):1425-1430.

68. Oga T, Nishimura K, Tsukino M, Hajiro T, Ikeda A, Izumi T. The effects of oxitropium bromide on exercise performance in patients with stable chronic obstructive pulmonary disease: a comparison of three different exercise tests. Am J Respir Crit Care Med. 2000;161(6):1897-1901.

69. Pepin V, Saey D, Whittom F, LeBlanc P, Maltais F. Walking versus cycling: sensitivity to bronchodilation in chronic obstructive pulmonary disease. Am J Respir Crit Care Med. 2005;172(12):1517-1522.

70. Zhang X, Waterman LA, Ward J, Baird JC, Mahler DA. Advantages of endurance treadmill walking compared with cycling to assess bronchodilator therapy. Chest. 2010;137(6):1354-1361.
71. Lederer DJ, Thomashow BM, Ginsburg ME, et al. Lung-volume reduction surgery for pulmonary emphysema: Improvement in body mass index, airflow obstruction, dyspnea, and exercise capacity index after 1 year. J Thorac Cardiovasc Surg. 2007;133(6):1434-1438.

72. Pepin V, Laviolette L, Brouillard C, et al. Significance of changes in endurance shuttle walking performance. Thorax. 2011;66(2):115-120.

73. Crisafulli E, Lorenzi MC, Gherardini G, et al. Test del cammino dei 6 minuti in pazienti con bronchopneupatia cronica ostruttiva: confronto cone senza incoraggiamento [Six-minute walk test in patients with chronic obstructive pulmonary disease: comparison with and without active coaching]. Rassegna di Patologia dell'Apparato Respiratorio. 2007;22(3):186-192.

74. Benzo RP, Paramesh S, Patel SA, Slivka WA, Sciurba FC. Optimal protocol selection for cardiopulmonary exercise testing in severe COPD. Chest. 2007;132(5):1500-1505.

75. Borghi-Silva A, Mendes RG, Toledo AC, et al. Adjuncts to physical training of patients with severe COPD: oxygen or noninvasive ventilation? Respir Care. 2010;55(7):885-894.

76. Casas A, Vilaro J, Rabinovich R, et al. Encouraged 6-min walking test indicates maximum sustainable exercise in COPD patients. Chest. 2005;128(1):55-61.

77. Davidson AC, Leach R, George RJ, Geddes DM. Supplemental oxygen and exercise ability in chronic obstructive airways disease. Thorax. 1988;43(12):965-971.

78. de Almeida FG, Victor EG, Rizzo JA. Hallway versus treadmill 6-minute-walk tests in patients with chronic obstructive pulmonary disease. Respir Care. 2009;54(12):1712-1716.

79. Dean NC, Brown JK, Himelman RB, Doherty JJ, Gold WM, Stulbarg MS. Oxygen may improve dyspnea and endurance in patients with chronic obstructive pulmonary disease and only mild hypoxemia. Am Rev Respir Dis. 1992;146(4):941-945.

80. Honeyman P, Barr P, Stubbing DG. Effect of a walking aid on disability, oxygenation, and breathlessness in patients with chronic airflow limitation. J Cardiopulm Rehabil. 1996;16(1):63-67.

81. Hsia D, Casaburi R, Pradhan A, Torres E, Porszasz J. Physiological responses to linear treadmill and cycle ergometer exercise in COPD. Eur Resp J. 2009;34(3):605-615.

82. Miyahara N, Eda R, Takeyama H, et al. Cardiorespiratory responses during cycle ergometer exercise with different ramp slope increments in patients with chronic obstructive pulmonary disease. Intern Med. 2000;39(1):15-19.

83. Ozalevli S, Ozden A, Gocen Z, Cimrin AH. Comparison of six-minute walking tests conducted with and without supplemental oxygen in patients with chronic obstructive pulmonary disease and exerciseinduced oxygen desaturation. Ann Saudi Med. 2007;27(2):94-100.

84. Rosa FW, Camelier A, Mayer A, Jardim JR. Evaluating physical capacity in patients with chronic obstructive pulmonary disease: Comparing the shuttle walk test with the encouraged 6-minute walk test. J Bras Pneumol. 2006;32(2):106-113.

85. Sandland CJ, Morgan MD, Singh SJ. Detecting oxygen desaturation in patients with COPD: Incremental versus endurance shuttle walking. Respir Med. 2008;102(8):1148-1152.

86. Swerts PM, Mostert R, Wouters EF. Comparison of corridor and treadmill walking in patients with severe chronic obstructive pulmonary disease. Phys Ther. 1990;70(7):439-442.

87. Morgan MD, Singh SJ. Assessing the exercise response to a bronchodilator in COPD: time to get off your bike? Thorax. 2007;62(4): 281-283. 


\section{Supplementary materials Complete Ovid search strings}

Table SI Embase ${ }^{\mathrm{TM}}$ search strings, search conducted January 22, 2013

\begin{tabular}{|c|c|c|}
\hline Search & Search strings & Results \\
\hline I & $\begin{array}{l}\text { chronic obstructive pulmonary disease.mp. or } \\
\text { exp chronic obstructive lung disease/ }\end{array}$ & 68,878 \\
\hline 2 & chronic obstructive lung disease.mp. & 65,527 \\
\hline 3 & chronic obstructive respiratory disease.mp. & 119 \\
\hline 4 & copd.mp. & 33,438 \\
\hline 5 & chronic obstructive airway disease.mp. & 378 \\
\hline 6 & chronic bronchitis.mp. or exp chronic bronchitis/ & 16,146 \\
\hline 7 & lung emphysema.mp. or exp lung emphysema/ & 19,606 \\
\hline 8 & chronic obstructive airway disease.mp. & 378 \\
\hline 9 & chronic airflow obstruction.mp. & 627 \\
\hline 10 & I or 2 or 3 or 4 or 5 or 6 or 7 or 8 or 9 & 103,379 \\
\hline II & $\begin{array}{l}\text { exp cardiopulmonary exercise test/or exp } \\
\text { exercise tolerance/or exp aerobic exercise/ } \\
\text { or exp exercise/or exp exercise test/ }\end{array}$ & 228,181 \\
\hline 12 & $\begin{array}{l}\text { (exercise or exercise capacity or exercise } \\
\text { tolerance).mp. }\end{array}$ & 302,038 \\
\hline 13 & $\begin{array}{l}\text { (clinically important difference or mcid or } \\
\text { clinically meaningful).mp. }\end{array}$ & 6,903 \\
\hline 14 & 11 or 12 or 13 & 311,378 \\
\hline 15 & $\begin{array}{l}\text { ('6 minute walk' or '6m walk' or '6 m walk' } \\
\text { or 'six minute walk' or '6MWD').mp. }\end{array}$ & 4,644 \\
\hline 16 & $\begin{array}{l}\text { (' } 12 \text { minute walk' or ' } 12 \mathrm{~m} \text { walk’ or ‘ } 12 \mathrm{~m} \text { walk’ } \\
\text { or 'twelve minute walk' or ' } \mathrm{I} 2 \mathrm{MWD} \text { ').mp. }\end{array}$ & 90 \\
\hline 17 & $\begin{array}{l}\text { ('shuttle walk’ or 'shuttle walking' or 'iswt' } \\
\text { or ' } 10 \text { metre walking' or ' } 10 \text { meter walking' } \\
\text { or 'ESWT').mp. }\end{array}$ & 1,010 \\
\hline 18 & cycle ergometer.mp. or exp bicycle ergometer/ & 5,540 \\
\hline 19 & bicycle ergometry.mp. or exp bicycle ergometry/ & 6,840 \\
\hline 20 & $\begin{array}{l}\text { (cycle ergometry or cycle ergometric or bicycle } \\
\text { ergometric).mp. }\end{array}$ & $\mathrm{I}, 72 \mathrm{I}$ \\
\hline 21 & treadmill.mp. or exp treadmill/ & 29,379 \\
\hline 22 & (short physical performance battery or sppb).mp. & 367 \\
\hline 23 & 15 or 16 or 17 or 18 or 19 or 20 or 21 or 22 & 45,996 \\
\hline 24 & 10 and 14 and 23 & 1,626 \\
\hline 25 & (test or assessment or capacity).mp. & $3,225,394$ \\
\hline 24 & 10 and 14 and 23 & $\mathrm{I}, 408$ \\
\hline 25 & (test or assessment or capacity).mp. & 1,099 \\
\hline
\end{tabular}

Table S2 Medline ${ }^{\circledR}$ search strings, search conducted January 22, 2013

\begin{tabular}{|c|c|c|}
\hline Search & Search string & Results \\
\hline I & $\begin{array}{l}\text { chronic obstructive pulmonary disease.mp. or } \\
\text { exp pulmonary disease, chronic obstructive/ }\end{array}$ & 31,239 \\
\hline 2 & chronic obstructive lung disease.mp. & 2,686 \\
\hline 3 & $\begin{array}{l}\text { exp lung diseases, obstructive/or chronic } \\
\text { obstructive respiratory disease.mp. }\end{array}$ & 150,257 \\
\hline 4 & copd.mp. & 21,567 \\
\hline 5 & chronic obstructive airway disease.mp. & 239 \\
\hline 6 & $\begin{array}{l}\text { chronic bronchitis.mp. or exp bronchitis, } \\
\text { chronic/ }\end{array}$ & 8,867 \\
\hline 7 & lung emphysema.mp. & 298 \\
\hline 8 & chronic obstructive airway disease.mp. & 239 \\
\hline 9 & chronic airflow obstruction.mp. & 502 \\
\hline 10 & I or 2 or 3 or 4 or 5 or 6 or 7 or 8 or 9 & 161,227 \\
\hline II & $\begin{array}{l}\text { exp exercise tolerance/or exp exercise test/ } \\
\text { or exercise.mp. or exp exercise/ }\end{array}$ & 239,508 \\
\hline 12 & (exercise capacity or exercise tolerance).mp. & 16,495 \\
\hline 13 & $\begin{array}{l}\text { (clinically important difference or mcid or } \\
\text { clinically meaningful).mp. }\end{array}$ & 4,675 \\
\hline 14 & 11 or 12 or 13 & 243,911 \\
\hline 15 & $\begin{array}{l}\text { (‘6 minute walk' or ‘ } 6 \mathrm{~m} \text { walk' or ‘ } 6 \mathrm{~m} \text { walk' } \\
\text { or 'six minute walk' or ' } 6 \mathrm{mwd} \text { ').mp. }\end{array}$ & 2,563 \\
\hline 16 & $\begin{array}{l}\text { (' } 12 \text { minute walk’ or ‘ } 12 \mathrm{~m} \text { walk’ or ‘ } 12 \mathrm{~m} \\
\text { walk' or 'twelve minute walk’ } \\
\text { or ' } 12 \mathrm{mwd} \text { ').mp. }\end{array}$ & 62 \\
\hline 17 & $\begin{array}{l}\text { ('shuttle walk' or 'shuttle walking' or 'iswt' } \\
\text { or ' } 10 \text { metre walking' or ' } 10 \text { meter walking' } \\
\text { or 'eswt').mp. }\end{array}$ & 644 \\
\hline 18 & \$cycle ergomet*.mp. & 4,838 \\
\hline 19 & treadmill.mp. & 20,912 \\
\hline 20 & $\begin{array}{l}\text { (short physical performance battery } \\
\text { or sppb).mp. }\end{array}$ & 247 \\
\hline 21 & 15 or 16 or 17 or 18 or 19 or 20 & 28,642 \\
\hline 22 & 10 and 14 and 21 & 1,278 \\
\hline 23 & (test or assessment or capacity).mp. & $1,939,77 \mid$ \\
\hline 24 & 10 and 14 and 21 and 23 & 1,065 \\
\hline 25 & limit 24 to (English language and humans) & 928 \\
\hline
\end{tabular}


Table S3 The Cochrane Library search strings, search conducted January 22, 2013

\begin{tabular}{|c|c|c|}
\hline Search & Search string & Results \\
\hline I & $\begin{array}{l}\text { MeSH descriptor: [Pulmonary Disease, } \\
\text { Chronic Obstructive] explode all trees }\end{array}$ & $\mathrm{I}, 845$ \\
\hline 2 & chronic obstructive pulmonary disease & 4,929 \\
\hline 3 & $\begin{array}{l}\text { MeSH descriptor: [Lung Diseases, Obstructive] } \\
\text { explode all trees }\end{array}$ & 12,759 \\
\hline 4 & chronic obstructive respiratory disease & 3,340 \\
\hline 5 & copd & 6,244 \\
\hline 6 & chronic obstructive airway disease & 4,348 \\
\hline 7 & $\begin{array}{l}\text { MeSH descriptor: [Bronchitis, Chronic] explode } \\
\text { all trees }\end{array}$ & 77 \\
\hline 8 & chronic bronchitis & 1,969 \\
\hline 9 & lung emphysema & 517 \\
\hline 10 & chronic obstructive airway disease & 4,348 \\
\hline II & chronic airflow obstruction & 416 \\
\hline 12 & $\begin{array}{l}\# 1 \text { or } \# 2 \text { or } \# 3 \text { or } \# 4 \text { or } \# 5 \text { or } \# 6 \text { or } \# 7 \\
\text { or } \# 8 \text { or } \# 9 \text { or } \# 10 \text { or } \# 11\end{array}$ & 18,973 \\
\hline 13 & $\begin{array}{l}\text { MeSH descriptor: [Exercise Tolerance] explode } \\
\text { all trees }\end{array}$ & $|, 43|$ \\
\hline 14 & MeSH descriptor: [Exercise Test] explode all trees & 5,816 \\
\hline 15 & MeSH descriptor: [Exercise] explode all trees & 11,528 \\
\hline 16 & exercise or exercise capacity or exercise tolerance & 38,220 \\
\hline 17 & $\begin{array}{l}\text { clinically important difference or mcid or clinically } \\
\text { meaningful }\end{array}$ & 7,450 \\
\hline 18 & $\# 13$ or $\# 14$ or $\# 15$ or $\# 16$ or \#17 & 45,480 \\
\hline 19 & $\begin{array}{l}\text { ' } 6 \text { minute walk' or ' } 6 \mathrm{~m} \text { walk' or ' } 6 \mathrm{~m} \text { walk' or 'six } \\
\text { minute walk' or ' } 6 \mathrm{mwd} \text { ' }\end{array}$ & 3,377 \\
\hline 20 & $\begin{array}{l}\text { ' } 12 \text { minute walk' or ' } 12 \mathrm{~m} \text { walk' or ' } 12 \mathrm{~m} \text { walk' or } \\
\text { 'twelve minute walk' or ' } 12 \mathrm{mwd} \text { ' }\end{array}$ & 2,233 \\
\hline 21 & $\begin{array}{l}\text { 'shuttle walk' or 'shuttle walking' or 'iswt' or '10 } \\
\text { metre walking' or ' } 10 \text { meter walking' or 'eswt' }\end{array}$ & 716 \\
\hline 22 & *cycle ergomet* & 2,392 \\
\hline 23 & treadmill & 3,759 \\
\hline 24 & short physical performance batter or sppb & 41 \\
\hline 25 & $\# 19$ or $\# 20$ or $\# 21$ or $\# 22$ or $\# 23$ or \#24 & 9,217 \\
\hline 26 & test or assessment or capacity & 211,756 \\
\hline 27 & $\# 12$ and $\# 18$ and $\# 25$ and $\# 26$ & 779 \\
\hline
\end{tabular}

International Journal of COPD

\section{Publish your work in this journal}

The International Journal of COPD is an international, peer-reviewed journal of therapeutics and pharmacology focusing on concise rapid reporting of clinical studies and reviews in COPD. Special focus is given to the pathophysiological processes underlying the disease, intervention programs, patient focused education, and self management protocols.

\section{Dovepress}

This journal is indexed on PubMed Central, MedLine and CAS. The manuscript management system is completely online and includes a very quick and fair peer-review system, which is all easy to use. Visit $\mathrm{http}: / / \mathrm{www}$. dovepress.com/testimonials.php to read real quotes from published authors. 